\title{
Schistosoma mansoni: ASPECTOS QUANTITATIVOS DA EVOLUCÃO DE CERCÁRIAS IRRADIADAS A NÍVEL DA PELE, PULMÕES E SISTEMA PORTA, EM CAMUNDONGOS
}

\author{
Gileno de Sá CARDoso (1) \& Paulo Marcos Zech CoELHo (2)
}

\begin{abstract}
RESUMO
Foi estudada a migração do Schistosoma mansoni (cepas LE e SJ) em oito grupos de camundongos albinos (Mus musculus) nāo isogênicos, infectados transcutaneamente com cerca de $\mathbf{4 5 0}$ cercárias nảo irradiadas (grupos controles) e irradiadas com $3 \mathrm{Krad}, 20 \mathrm{Krad}$ e $40 \mathrm{Krad}$ de radiaçâo gama proveniente de cobalto-60. $\mathrm{Na}$ pele, observou-se uma diminuiçāo progressiva das taxas de recuperaçāo em função do tempo e, nos pulmōes e sistema porta, verificou-se uma relaçāo inversa signifi. cativa entre as taxas de recuperação total e as doses de irradiação. A dose de 20 Krad praticamente impede a migração dos parasitos, de ambas as cepas, dos pulmōes até o sistema porta, enquanto a de $40 \mathrm{Krad}$ praticamente impede a migraçāo dos mesmos da pele para os pulmões.
\end{abstract}

UNITERMOS: Schistosoma mansoni; Irradiação de cercárias; Evolução de vermes irradiados.

\section{INTRODUÇÃO}

$\mathrm{Na}$ esquistossomose mansoni experimental o uso de cercárias ou esquistossômulos irradiados induz a um estado de imunoproteção equivalente ao produzido por uma infecçảo madura (imunidade concomitante), tendo a vantagem de não provocar alteraçóes imunopatológicas significativas no hospedeiro.
As tentativas de obter imunoproteção em animais de laboratório com formas irradiadas de Schistosoma mansoni, iniciadas por VILLE LA et al. ${ }^{18}$, têm sido inúmeras e tiveram um grande impulso após a constatação feita por BICKLE \& $\mathrm{JAMES}^{3}$, de que a criopreservaçāo nāo altera as propriedades das cercárias ou esquistossômulos irradiados de induzirem imunoproteçāo.

(1) Laboratório de Parasitologia. Departamento de Morfologia, Centro de Ciēncias Biológicas e da Saúde, Universidade Federal de Sergipe. Aracajú, Sergipe, Brasil.

(2) Departamento de Parasitologia e Grupo Interdepartamental de Estudos sobre Esquistossomose (GIDE), Instituto de Cièncias Biológicas da Universidade Federal de Minas Gerais. Belo Horizonte, Minas Gerais, Brasil.

Endereço para correspondência: Prof. Paulo Marcos Zech Coelho. Coordenador do GIDE. Instituto de Ciéncias Biologicas da Universidade Federal de Minas Gerais. Caixa Postal 2486. CEP 30161 Belo Horizonte, Minas Gerais, Brasil.

Abreviaturas usadas neste trabalho:

CDTN = Centro de Desenvolvimento da Tecnologia Nuclear

GIDE = Grupo Interdepartamental de Estudos sobre Esquistossomose

ICB = Instituto de Cièncias Biológicas

NUCLEBRAS = Empresas Nucleares Brasileiras S.A.

UFMG = Universidade Federal de Minas Gerais 
CARdoso, G. de S. \& COELho, P. M. Z. - Sehistosoma mansoni: aspectos quantitativos da evoluçá de cercárias irradiadas a nivel da pele. pulmões e sistema porta, em camundongos. Rev. Inst. Med. trop. S. Paulo, 31 (5): 313321. 1989.

A grande maioria desses estudos, no entanto, só trata do destino no vertebrado da popu lação dos vermes não irradiados (isto é, do desafio) e somente alguns estudos apresentam dados mais consistentes sobre o comportamento dos vermes irradiados em hospedeiros nâo imunizados previamente ${ }^{2.4 .7}$

Assim, verifica-se pela revisāo da literatura pertinente que nāo há ainda um estudo detalhado que aborde os efeitos da atenuação de cer. cárias de Schistosoma mansoni com raios gama sobre a sua capacidade de migração e sobrevivência no hospedeiro vertebrado. No presente estudo, a recuperação dos parasitos, oriundos de cercárias das cepas $\mathbf{L E}$ e SJ do $\mathbf{S}$. mansoni irradiadas com 3, 20 e $40 \mathrm{Krad}$, foi quantificada a nível de pele, pulmóes e sistema porta de camundongos. Tal estudo é justificado pelo exposto anteriormente e pelo fato de que as cepas LE e SJ do S. mansoni, importantes na epidemiologia da esquistossomose no Brasil, apesar de muito estudadas sob diversos aspectos, ainda não o foram em estudos com o uso de radiaçāo gama.

\section{MATERIAL E MÉTODOS}

\section{Animais e parasitos}

Camundongos albinos (Mus musculus), nāo isogênicos, fémeas, com cerca de 30 dias de nasci. dos, foram infectados transcutaneamente, de acordo com a técnica de BARBOSA et al. ${ }^{1}$, com cerca de 450 cercárias de Schistosoma mansoni da cepa LE (de Belo Horizonte-MG, mantida no GIDE em Biomphalaria glabrata há mais de 25 anos) e da cepa SJ (de São José dos Campos-SP, mantida no ICB em B. glabrata, com repassagens sucessivas em Biomphalaria tenagophila, há mais de 10 anos). Os planorbídeos, nascidos e criados em laboratório, segundo técnica de FREITAS ${ }^{6}$, foram infectados de acordo com a técnica de PELLEGRINO \& $\mathrm{KATZ}^{13}$.

\section{Irradiação das cercárias}

Oito grupos experimentais foram definidos usando-se cercárias nāo irradiadas (grupos controles) e irradiadas com 3, 20 e $40 \mathrm{Krad}$, das duas cepas. As amostras de cercárias a serem irradiadas eram transportadas para o CDTN da
NUCLEBRÁS, no campus da Pampulha, onde eram expostas à radiação gama proveniente da bomba de cobalto-60, sendo a dose de irradiação equivalente ao tempo de exposiçáo das cercárias à essa fonte de radiaçào.

\section{Recuperação dos parasitos}

Do 1: ao 11: dia da infecção, lotes de 6 (seis) camundongos para cada grupo experimental e dia considerado eram sacrificados e os esquistos sômulos da pele recuperados, conforme técnica de BARBOSA et al. ${ }^{\text {. }}$

Do 3: dia após a infecção até o último dia de observação de cada grupo, para ambas as cepas, foram sacrificados lotes de 6 (seis) camundongos para cada grupo e para cada dia de observação, para recuperação de vermes dos pulmôes, conforme técnica descrita por BARBOSA et al. ${ }^{1}$.

A partir do 8: dia após a infecçâo até o último dia de observação de cada grupo, lotes de 6 (seis) camundongos, para cada grupo e para cada dia de observação, foram sacrificados para recuperaçāo de vermes do sistema porta, de acordo com a técnica de PELLEGRINO \& SIQUEIRA ${ }^{14}$. Os últimos dias de recuperaçāo de vermes dos pulmōes e sistema porta dos grupos estudados foram: grupo controle -47 . dia, por causa da altíssima taxa de mortalidade dos camundongos, devida à elevada carga infectante (aproximadamente 450 cercárias normais): para o grupo $3 \mathrm{Krad}$ foi estipulado o 90 " dia para determinar a longevidade dos vermes sobreviventes; para o grupo de $20 \mathrm{Krad}$ foi determinado o dia 40 ., pois a partir desta data não se encontraram mais parasitos nos animais e, por esta mesma razão, o dia 11: foi determinado para o grupo $40 \mathrm{Krad}$.

\section{Análise estatistica}

$\mathrm{Na}$ análise estatística dos resultados foi utilizado o método da análise de variância, trabalhando-se com proporçōes baseadas no rendimento cercárias/vermes e ajustadas pelo método de transformaçāo arcoseno ou angular, de acordo com SNEDECOR \& COCHRAN ${ }^{17}$.

\section{RESULTADOS}

\section{Recuperação de esquistossômulos na pele}

Nos gráficos 1 e 2 estão representadas as porcentagens médias de recuperação de esquistos- 


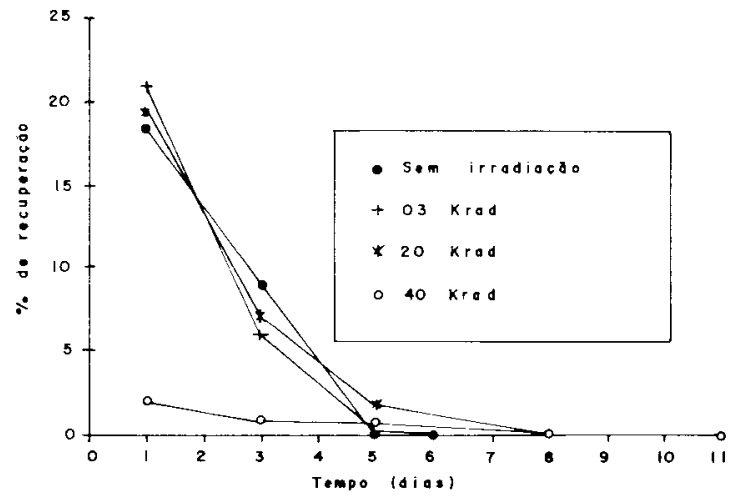

Gráfico 1 - Porcentagens medias de recuperação de esquistos somulos da pele oriundos de cercárias, da cepa LE do S. mansoni, nāo irradiadas e irradiadas com $3 \mathrm{Krad}, 20 \mathrm{Krade} 40 \mathrm{Krad}$ de radiaça gama proveniente de cobalto-60. em camundongos infectados transcutaneamente com cerca de 433 icontrolesi. $394(3 \mathrm{Krad}), 324(20 \mathrm{Krad})$ e $336(40 \mathrm{Krad}$ ) cercárias.

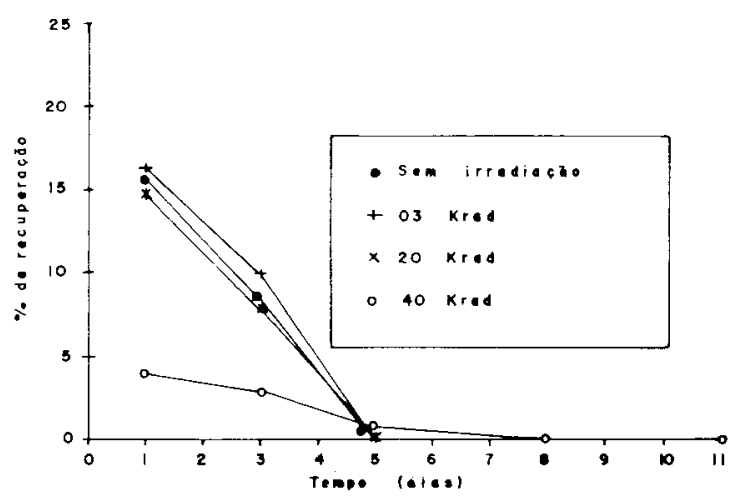

Gráfico 2 - Porcentagens mèdias de recuperaçāo de esquistos somulos da pele oriundos de cercarias. da cepa SJ do S. mansoni, nảo irradiadas e irradiadas com $3 \mathrm{Krad}, 20 \mathrm{Krad}$ e 40 Krad de radiaçáo gama proveniente de cobalto-60. em camundongos infectados transcutaneamente com cerca de 409 (con troles 465 ( $3 \mathrm{Krad}), 389(20 \mathrm{Krad})$ e $307 / 40 \mathrm{Krad})$ cercarias.

sômulos da pele oriundos de cercárias, das cepas LE e SJ do S. mansoni, nāo irradiadas e irradiadas com $3 \mathrm{Krad}, 20 \mathrm{Krad}$ e $40 \mathrm{Krad}$ de radiação gama proveniente de Co-60.

Os resultados mostram que, na pele, houve uma diminuição progressiva da taxa de recuperação de esquistossômulos em função do tempo. até o seu desaparecimento no 8. dia. em ambos os experimentos com as cepas LE e SJ. A análise de variância desses resultados mostrou que não houve diferença estatisticamente significativa $(\mathrm{P}<0,01)$ na recuperação de esquistossômulos controles e irradiados com $3 \mathrm{Krad}$ e $20 \mathrm{Krad}$, em ambos os experimentos.

\section{Recuperação de esquistossômulos nos pulmões}

Nos gráficos 3 e 4 estão representados as porcentagens médias de recuperaçāo de esquistossómulos dos pulmóes oriundos de cercárias, das cepas LE e SJ do $\mathbf{S}$. mansoni, não irradiadas e irradiadas com $3 \mathrm{Krad}, 20 \mathrm{Krad}$ e $40 \mathrm{Krad}$ de radiação gama proveniente de Co-60.

Os resultados mostram que, nos pulmóes, os esquistossómulos controles e irradiados com

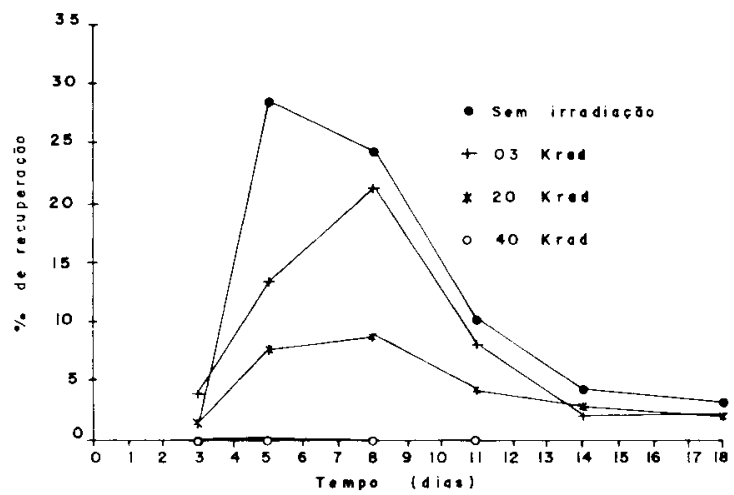

Gráfico 3 - Porcentagens médias de recuperaçảo de esquistossómulos dos pulmóes oriundos de cercárias. da cepa LE do S. mansoni. nāo irradiadas e irradiadas com $3 \mathrm{Krad}, 20 \mathrm{Krad}$ e $40 \mathrm{Krad}$ de radiacâo gama proveniente de cobalto-60, em camundongos infectados transcutaneamente com cerca de 433 (controles). 394 (3 Krad), 324 (20 Krad) e 336 (40 Kradıcercárias.

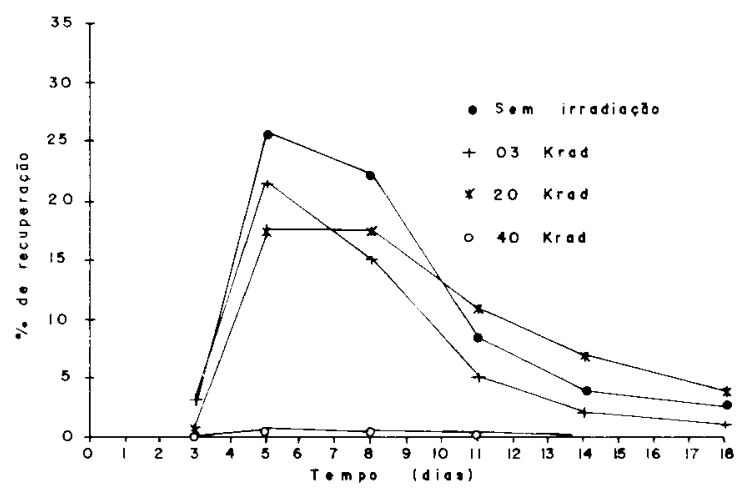

Gráfico 4 - Porcentagens médias de recuperaçâo de esquistos sômulos dos pulmôes oriundos de cercárias, da cepa $\mathrm{SJ}$ do S. mansoni. nāo irradiadas e irradiadas com $3 \mathrm{Krad}, 20 \mathrm{Krad}$ e $40 \mathrm{Krad}$ de radiaça gama proveniente de cobalto 60 , em camundongos infectados transcutaneamente com cerca de 409 (controles). $465(3 \mathrm{Krad}), 389(20 \mathrm{Krad})$ e 307 (40 Krad) cercárias. 
CARDOSO, G. de S. \& COELHO, P. M. Z. - Schistosoma mansoni: aspectos quantitativos da evoluçáo de cercárias irradiadas a nivel da pele, pulmōes e sistema porta, em camundongos. Rev. Inst. Med. trop. S. Paulo, $31(5)$ : 313 321, 1989

3,20 e $40 \mathrm{Krad}$, de ambas as cepas, foram detec tados a partir do 3 ? dia após a infecçảo e os picos máximos de recuperação ocorreram entre o 5 . e 8. dias. A análise de variância desses resultados mostrou que os grupos de esquistossômulos controles e irradiados nessas doses apresentaram diferenças estatisticamente significativas $(P<$ 0,01 i nas taxas de recuperação, em ambos os ex perimentos, sendo que as maiores porcentagens ocorreram nos grupos de parasitos que não foram irradiados ou que receberam doses menores de irradiação.

\section{Recuperação dos parasitos do sistema porta}

Nos gráficos 5 e 6 estāo representadas as porcentagens médias de recuperaçāo de parasitos

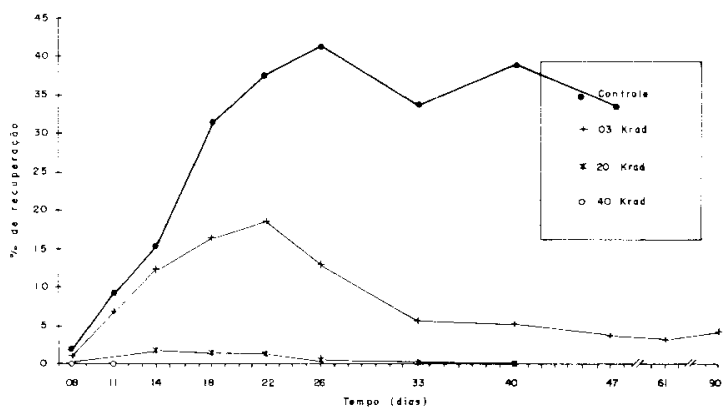

Gráfico 5 - Porcentagens médias de recuperaçảo de vermes do sistema porta da cepa LE do S. mansoni, controles e irradia dos com $3 \mathrm{Krad}, 20 \mathrm{Krad}$ e $40 \mathrm{Krad}$ de radiaço gama prove niente de cobalto-60. em camundongos irradiados transcuta neamente com cerca de 433 (controles), 394 (3 Krad), 324 (20 Krad) e 336 (40 Krad) cercárias.

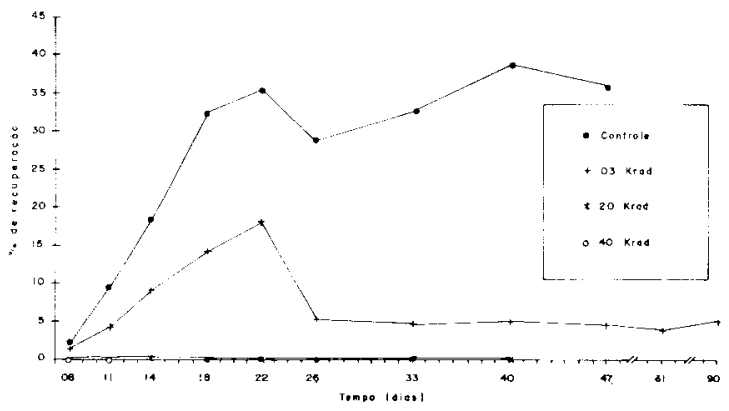

Gráfico 6 - Porcentagens médias de recuperaçāo de vermes do sistema porta, da cepa SJ do $\mathbf{S}$. mansoni, controles e irradia dos com $3 \mathrm{Krad}, 20 \mathrm{Krad} \mathrm{c} 40 \mathrm{Krad}$ de radiaçāo gama prove niente de cobalto 60 , em camundongos infectados transcuta. neamente com cerca de 409 (controles), 465 (3 Krad), 389 (20 Krad) e 307 140 Krad) cercárias do sistema porta oriundos de cercárias das cepas LE e SJ do S. mansoni, nāo irradiadas e irradiadas com $3 \mathrm{Krad}, 20 \mathrm{Krad}$ e $40 \mathrm{Krad}$ de radiação gama provenientes de Co-60.

Os resultados mostram que, no sistema porta, os vermes controles e irradiados com $3 \mathrm{Krad}$, de ambas as cepas, chegam a partir do 8 . dia e a faixa ótima de recuperação se verificou entre o 18. e 22\% dias. A análise de variância desses resultados mostrou que houve uma redução es tatisticamente significativa ( $\mathrm{P}<0,01$ ) na recupe. ração dos vermes irradiados com $3 \mathrm{Krad}$ em rela çāo aos controles, das duas cepas.

\section{DISCUSSÃO}

Pelos resultados obtidos, verifica-se que a recuperação dos esquistossômulos irradiados com doses até $20 \mathrm{Krad}$, na pele de camundongos. é idêntica à dos parasitos normais náo irradiados, independentemente da cepa utilizada. Isto está de acordo com GHANDOUR \& WEBBE que, utilizando uma cepa de Schistosoma mansoni de Porto Rico, mantida em Biomphalaria glabrata, nāo encontraram diferença estatisticamente significativa na porcentagem média de mortalidade de esquistossômulos da pele de camundongos infectados com cercárias irradiadas com $6 \mathrm{Krad}$ de radiaçāo gama proveniente de Co $60(32,5 \%)$ em relação à verificada em camundongos controles infectados com cercárias não irradiadas $(28,5 \%)$. No presente estudo, somente o grupo de esquistossômulos irradiados com 40 $\mathrm{Krad}$, de ambas as cepas, apresentou uma reduçāo estatisticamente significativa na sua recuperaçāo em relaçāo aos demais grupos, a nível da pele. Pode-se então dizer que a dose de $40 \mathrm{Krad}$ diminui significativamente a sobrevida dos esquistossômulos a nível da pele. Isto está de acordo com BICKLE et al. ${ }^{2}$ que, utilizando uma cepa de $\mathbf{S}$. mansoni de Porto Rico, mantida em $\mathbf{B}$. glabrata, verificaram que a maioria dos esquis tossômulos, irradiados com $40 \mathrm{Krad}$ de radiaçāo gama proveniente de Co-60 e inoculados intramuscularmente em camundongos, sāo destruidos no local da infecção. HSU et al. ${ }^{\circ}$ observaram que todos os esquistossômulos de Schistosoma japonicum, irradiados com $48 \mathrm{Krad}$ de raios $\mathrm{X}$. sāo destruídos na pele. LICHTENBERG \& SADUN ${ }^{9}$, baseados no grau de inflamação estimulado pela morte e desintegraçāo de cercárias de uma cepa 
CARDOSO, G. de S. \& COELHO, P. M. Z. - Schistosoma mansoni: aspectos quantitativos da evoluçảo de cercárias irradiadas a nível da pele, pulmōes e sistema porta. em camundongos. Rev. Inst. Med. trop. S. Paulo, 31(5): 313 321, 1989.

de S. mansoni de Porto Rico mantida em B. glabrata e irradiadas com 50.000 rep (roentgens equivalent physical) (aproximadamente 50 $\mathrm{Krad}$ ) de radiaçào gama proveniente de Co-60, verificaram que o quadro patológico principal em camundongos a elas expostos foi o de dermatite cercariana com ulceração e vasculite a nível da pele, não havendo comprometimento dos pulmóes e fígado. FORD et al. ${ }^{5}$ obtiveram uma recuperação máxima de $0.5 \%$ nos pulmóes e náo detectaram parasitos no figado de ratos infectados transcutaneamente com 3.000 cercárias, de uma cepa de S. mansoni de Porto Rico, mantida em B. glabrata, irradiadas com $40 \mathrm{Krad}$ de radiação gama proveniente de Co-60, donde concluíram que a maioria desses parasitos morrem na pele. Deve-se acrescentar que os esquistossômulos irradiados nas 3 diferentes doses (3,20 e $40 \mathrm{Krad})$, à exemplo dos controles não irradiados, de ambas as cepas, foram detectados na pele ainda no 8: dia após a infecção e não mais no 11: dia e, portanto, desapareceram desse local no intervalo do 8: ao 11: dia após a infecção. Com relação aos esquis tossômulos controles, estes resultados estão de acordo com os de BARBOSA et al. ${ }^{1}$, que detectaram um ( 1 ) esquistossômulo $(0,045 \%$ ) na pele de um camundongo examinado ainda no 10 . dia após a infecçāo com cerca de 440 cercárias nào irradiadas, da cepa $L E$ de $S$. mansoni mantida em B. glabrata.

No que diz respeito à recuperação a nível pulmonar, utilizando-se os picos máximos de recuperaçāo, pode-se dizer que existe uma relação inversa estatisticamente significativa entre as taxas de recuperação de esquistossômulos dos pulmōes e as doses de irradiaçāo utilizadas nos parasitos, das duas cepas. Isto está de acordo com BICKLE et al.2 que, utilizando cercárias, cepa de Porto Rico, normais e irradiadas com 2.3, $4,10,20$ e $40 \mathrm{Krad}$ de radiação gama, detectaram picos de recuperação de esquistossômulos nos pulmões, proporcionalmente mais baixos para os parasitos submetidos a doses crescentes de irradiação. Contraditoriamente, ERIKSON ${ }^{4}$ detectou porcentagens de recuperaçāo de esquistossômulos, irradiados com $8 \mathrm{Krad}$ de radiaçāo gama proveniente de Co-60, mais elevadas que as de esquistossômulos nāo irradiados, cepa de Porto Rico, nos pulmōes, do 11: ao 35: dia apósinfeccão, indo de encontro aos nossos resultados e demais citados na literatura. Verificando-se a redução estatisticamente significativa que houve nos picos de recuperação, nos pulmóes, dos esquistossômulos irradiados com $3 \mathrm{Krad}$ em reIação aos controles, pode-se inferir que uma pequena proporçāo desses parasitos nāo alcança os pulmōes ou neles sāo destruídos. Isto está de acordo com GHANDOUR \& WEBBE ${ }^{7}$, que observaram, no 7 dia após a infecção, um pico de recuperação de esquistossômulos irradiados com $6 \mathrm{Krad}$ de radiação gama proveniente de Co-60 (10,9\%) significativamente menor que o de esquistossômulos não irradiados $(17,1 \%)$, nos pulmões de camundongos infectados com cercárias de uma cepa de Porto Rico. LICHTEN. BERG \& SADUN ${ }^{9}$, baseados nas alterações patológicas provocadas pela morte e desintegraçāo de esquistossômulos, verificaram numerosos focos granulomatosos nos pulmōes de camundongos expostos a cercárias irradiadas com 5.000 rep (aproximadamente $5 \mathrm{Krad}$ ) de radiação gama proveniente de Co-60, cepa de Porto Rico, sugerindo que o principal local de destruição desses parasitos foi os pulmòes. Em funçāo da redução estatisticamente significativa verifi. cadanos picos de recuperação, nos pulmóes, dos esquistossômulos irradiados com $20 \mathrm{Krad}$ em relaçāo aos controles, pode-se dizer que uma proporção relativamente grande desses parasitos ou nāo alcança os pulmōes ou neles é destruída. Os nossos resultados $(8,59 \%$ para a cepa LE e $17,35 \%$ para a cepa SJ), obtidos no dia 8 pós-infecção, estão de acordo com os de FORD et al. ${ }^{5}$, que obtiveram uma recuperaçāo máxima de $14,8 \%$ no dia 7 pós-infecção, nos pulmōes de ratos infectados transcutaneamente com 3.000 cercárias, de uma cepa de $\mathbf{S}$. mansoni de Porto Rico mantida em B. glabrata, irradiadas com $20 \mathrm{Krad}$ de radiaçāo gama proveniente de Co 60 , donde os autores concluíram que a maioria des ses parasitos morrem nos pulmões. MASTIN et al. ${ }^{11}$. utilizando uma técnica histologica quanti tativa, verificaram que poucos esquistossômulos irradiados com $20 \mathrm{Krad}$ de radiação gama proveniente de Co-60 sào mortos na pele e a maioria permanece nos pulmōes onde sāo mortos até o dia 21 após a infecçào transcutànea com 200 cercárias de uma cepa de $\mathbf{S}$. mansoni de Porto Rico mantida em B. glabrata.

Alguns autores detectaram taxas de recuperaçāo, nos pulmões, diferentes das nossas. Assim, MANGOLD \& DEAN ${ }^{10}$, utilizando uma ce- 
CARDOSO, G. de S. \& COELHO, P. M. Z. - Schistosoma mansoni: aspectos quantitativos da evoluçāo de cercárias irradiadas a nivel da pele, pulmóes e sistema porta, em camundongos. Rev. Inst. Med. trop. S. Paulo, 31 (5): 313 321. 1989.

pa de S. mansoni de Porto Rico mantida em B. glabrata, verificaram que $90 \%$ dos esquistos sômulos irradiados com $20 \mathrm{Krad}$ de radiação ga ma proveniente de Co-60 foram detectados, no dia 8 pós-infecção, nos pulmōes de camundongos infectados pela pele da cauda. As taxas de recu peraçāo por nós encontradas foram menores, provavelmente porque esses autores utilizaram a técnica da auto-radiografia pela qual são de tectados também os parasitos mortos (marcados biossinteticamente com selênio metionina), en quanto que na técnica de EARBOSA et al. ${ }^{1}$ so mente sāo recuperados os parasitos vivos com ca pacidade de migrarem dos tecidos para a soluçāo de Hanks contida em um Becker. Por outro lado, MILLER \& SMITHERS ${ }^{12}$ obtiveram uma recu peraçāo máxima de apenas $2,3 \%$ no dia 8 pós-infecção, nos pulmóes de camundongos infectados transcutaneamente com 400 cercárias, de uma cepa de $\mathbf{S}$. mansoni de Porto Rico mantida em B. glabrata, irradiadas com $20 \mathrm{KR}$ (aproximada mente $20 \mathrm{Krad}$ ) de radiaçāo gama proveniente de Co-60, donde eles concluiram que a maioria desses parasitos permanece na pele. As taxas de recuperação por nós encontradas foram maio res porque esses autores utilizaram a técnica de SHER et al. ${ }^{16}$, que provavelmente deve ser me nos eficiente que a de BARBOSA et al. ${ }^{1}$ para a recuperaçào de esquistossômulos dos pul mòes.

Os esquistossômulos irradiados com 3 e 20 Krad, à exemplo dos controles não irradiados. foram detectados nos pulmóes a partir do 3: dia após a infecçāo e a faixa ótima de recuperação verificou-se entre o 5." e 8". dia para esses grupos. A partir do 11: dia houve uma diminuiçáo pro gressiva nas taxas de recuperaçâo, em função do tempo, e depois do 33: dia elas se tornaram residuais até os dias finais de observação para esses grupos (gráficos 3 e 4 ). Esses resultados corroboram os de BARBOSA et al. ${ }^{1}$ que verifica ram, pela primeira vez na literatura, que os es quistossômulos permanecem, desde o 3 até o último dia de observação, nos pulmóes de ca mundongos infectados transcutaneamente com 440 (47: dia) e 65 (67. dia) cercárias da cepa LE de $\mathbf{S}$. mansoni, sendo que no 5 " e 7 " dias ocorre ram os picos máximos de recuperaçāo, para ca da infecção. ERICKSON ${ }^{4}$ nảo conseguiu detec tar esquistossômulos, irradiados com $8 \mathrm{Krad}$ de radiaçào gama proveniente de Co-60, após o 29 .' dia de observação nos pulmōes de camundongos infectados com 450 cercárias de $\mathbf{S}$. mansoni, cepa de Porto Rico. Acreditamos que o encontro de vermes irradiados, nos pulmōes, até os dias finais de observaçāo, por nós verificado, foi devido à sensibilidade do método empregado na recupe raçāo dos esquistossômulos.

Os esquistossômulos irradiados com 40 Krad somente foram detectados nos pulmóes, em porcentagens insignificantes, a partir do 5 .' dia, sendo que os da cepa $S J$ ai permaneceram residuais até o último dia de observação desse grupo (11), enquan to que os da cepa LE somente foram detectados no 5: dia pós-infecçào. Pode se então dizer que a dose de $40 \mathrm{Krad}$, além de diminuir a sobrevida dos esquistossômulos a nivel da pele, praticamente impede também a migra ção destes da pele até os pulmôes. Isto está de acordo com BICKLE et al. 2, que detectaram so mente uma taxa residual de parasitos, irradia dos com $40 \mathrm{Krad}$, nos pulmōes de camundongos infectados intramuscularmente com 600 cercá rias de S. mansoni, cepa de Porto Rico. Em contraposição, MANGOLD \& DEAN ${ }^{10}$, utilizando a técnica da auto-radiografia, verificaram que no dia 8 pós-infecçāo, 45 a $93 \%$ de esquistossómulos, irradiados com $50 \mathrm{Krad}$ de radiação gama proveniente de Co-60, migraram para os pulmóes, no dia 21 pós-infecção, acima de $90 \%$ desses para sitos irradiados com $50 \mathrm{Krad}$ foram detectados nos pulmōes e $50 \%$ dos parasitos irradiados com $90 \mathrm{Krad}$ migraram para os pulmoes de camun dongos infectados transcutaneamente com cer cárias de S. mansoni, cepa de Porto Rico. Como já foi discutido anteriormente, isto pode ser ex plicado, em parte, em funçāo da diferença entre as técnicas utilizadas.

Considerando os picos máximos de recupe ração, pode-se então dizer que, a exemplo do que ocorre nos pulmões, também existe uma re laçào inversa estatisticamente significativa en tre as taxas de recuperaçāo de vermes do siste ma porta e as doses de irradiação utilizadas, para ambas as cepas.

No 26: dia após a infecção, as taxas de recuperação dos vermes irradiados com $3 \mathrm{Krad}$ sofre ram uma recução estatisticamente significativa e a partir do 33 : dia se mantiveram em uma proporçāo constante até o último dia de observação 
CARDOSO, G. de S. \& COELHo, P. M. Z. - Schistosoma mansoni: aspectos quantitativos da evolucao de cercárias irradiadas a nivel da pele, pulmòes e sistema porta, em camundongos. Rev. Inst. Med. trop. S. Paulo, 31 15) 313321. 1989.

desse grupo (90"), enquanto que as taxas dos vermes controles de ambas as cepas permaneceram elevadas desde o 18: dia a té oúltimo dia de obser vaçāo desse grupo (47"). Considerando essa redu ção que houve a partir do 33: dia após a infecçào, pode-se então dizer que a dose de $3 \mathrm{Krad}$ diminui significativamente a sobrevida dos vermes no sistema porta após esse período de infecçāo. Isto está de acordo com BICKLE et al. ${ }^{2}$, que observa ram que vermes irradiados com $2,3 \mathrm{Krad}$ de radiaçào gama apareceram no figado inicialmente em números comparáveis aos dos parasitos náo irradiados, mas, entre os 12 e 15 dias pós-infecção ocorreu uma redução marcante dos vermes irradiados até o final das observaçoes (26: dia), indi cando que houve morte desses vermes no fígado. PERLOWAGORA-SZUMLEWICZ ${ }^{15}$ utilizando uma cepa de S. mansoni de Porto Rico, mantida em B. glabrata. observou que vermes irradiados com $2 \mathrm{Krad}$ e 2,5 $\mathrm{Krad}$ de raio $\mathrm{X}$ foram recupe rados do sistema porta de camundongos infecta dos com 300 cercárias irradiadas e 100 normais. em taxas reduzidas em relação aos não irradia dos, durante todo o período de observação que foi do 28 ao 288 . dia. HSU et al. ${ }^{8}$. através de estu do histopatológico em camundongos, observaram que esquistossomulos de $\mathbf{S}$. japonicum irradiados com 1,7, 3 e $6 \mathrm{Krad}$ de raios $\mathrm{X}$ foram des truídos no fígado.

LICHTENBERG \& SADUN ${ }^{9}$ baseados nas alteraçôes patológicas estimuladas pela morte e desintegração de vermes, observaram que em camundongos expostos a cercárias, irradiadas com 2.500 rep (aproximadamente $2,5 \mathrm{Krad}$ ) de radiaçào gama proveniente de Co-60, cepa de Porto Rico, foram vistos numerosos focos de ne crose e granulomas no fígado, sendo este o quadro patológico principal.

Os vermes, de ambas as cepas, irradiados com $20 \mathrm{Krad}$ chegaram ao sistema porta a partir do 8: dia, em porcentagens insignificantes, e ai permaneceram residuais até o penúltimo dia de observação para a cepa LE (26.) e último para a cepa $\mathbf{S J}$ (33").

Assim, como já foi dito anteriormente, a dose de $20 \mathrm{Krad}$ diminui a sobrevida dos esquistossô mulos a nível dos pulmóes e, como vemos agora. praticamente também impede a sua migraçāo dos pulmóes até o sistema porta. Isto está de acordo com MILLER \& SMITHER ${ }^{12}$, que en contraram, no 21 " dia pós infecção, uma porcen tagem de recuperação de $0,1 \%$ de vermes irradia dos, com $20 \mathrm{Krad}$ de radiação gama proveniente de Co-60, no fígado de camundongos infectados transcutaneamente com 400 cercárias de $\mathbf{S}$. mansoni, cepa de Porto Rico. MANGOLD \& DEAN ${ }^{1 /}$ observaram que, no dia 21 pós-infecçāo, somente uma pequena quantidade de esquistossomulos irradiados com $20 \mathrm{Krad}$ de radiaçāo gama prove niente de co 60 foram detectados, através da téc. nica da auto radiografia, no fígado de camun dongos infectados transcutaneamente com cercárias de uma cepa de Porto Rico. BICKLE et al." observaram que a dose de $20 \mathrm{Krad}$ de radia çāo gama proveniente de Co-60 impediu a migra ção de quase todos os parasitos ao figado, em camundongos infectados intramuscularmente com 600 esquistossômulos de uma cepa de $\mathbf{s}$. mansoni de Porto Rico, concluindo que a morte desses parasitos irradiados com $20 \mathrm{Krad}$ ocorreu nos músculos, vias de migração para os pulmões e nos pulmóes. Porém, nos nossos resultados. observamos que não houve reduçảo significativa nas taxas de recuperação dos vermes irradiados com $20 \mathrm{Krad}$ obtidos da pele em relaçào aos con troles e, talvez, isso tenha ocorrido devido ao fato de que a injeção intramuscular dificulta a saída dos esquistossômulos do local da infecção. tornando os mais propensos à destruiçào no lo cal. por não ser essa a via normal de infecção.

Somente um (1) verme irradiado com 40 Krad da cepa $L E$ foi detectado no sistema porta (no 8. dia pós-infecçāo) e nenhum da SJ, durante todo o período de observação. Assim, como já foi dito anteriormente, a dose de $40 \mathrm{Krad}$ diminui a sobrevida dos esquistossómulos a nível da pe le, impedindo praticamente a sua migração aos pulmôes e, como conseqüencia, também ao sis tema porta. Isto está de acordo com BICKLE et al. ${ }^{2}$, que detectaram somente parasitos resi duais, irradiados com $40 \mathrm{Krad}$ de radiaçāo gama proveniente de Co-60, no fígado de camundongos infectados intramuscularmente com 600 cercá rias, de uma cepa de Porto Rico, concluindo que a quase totalidade desses parasitos não saem do local da infecção. MANGOLD \& DEAN ${ }^{1 / \text { " veri. }}$ ficaram que, no dia 21 pós-infecção, somente um (1) esquistossômulo irradiado com $50 \mathrm{Krad}$ e um (1) com $90 \mathrm{Krad}$ de radiação gama proveniente de Co 60 , foram detectados no figado de camun 
CARIOSO. G. de S. \& COELHO. P. M. Z. - Schistosoma mansoni: aspectos quantitativos da evoluça de cercárias irradiadas a nivel da pele, pulmoes e sistema porta. em camundongos. Rev. Inst. Mcd. trop. S. Paulo, $31(5): 313321$. 1989.

dongos infectados transcutaneamente com cer cárias de uma cepa de Porto Rico, através da técnica de auto-radiografia.

Observando-se as taxas de recuperaçảo to tal de vermes da cepa LE ES, dos grupos contro les e irradiados ( 3,20 e $40 \mathrm{Krad})$, verifica-se que nào ocorreram diferenças estatisticamente sig nificativas nas comparaçôes dos respectivos gru pos inter-cepas.

\section{SUMMAR Y}

Schistosoma mansoni: quantitative aspects of the evolution of gamma-irradiated cercariae at the skin, lungs, and portal system, in mice.

The migration of Schistosoma mansoni ( $\mathrm{LE}$ and SJ strains I has been studied in eight groups of outbred Swiss albino mice (Mus musculus). which were previously infected with ca 450 cerca riae, transcutaneously. The infection of mice was performed with non irradiated cercariae control groups), or with gamma-irradiated cercariae, at the schedule of 3,20 and $40 \mathrm{Krad}$. Regarding the skin. a progressive decrease was detected for the recovery rates, related to the time of infec tion. As far as the lungs and portal system are concerned, a significant inverse correlation was observed between the total recovery rate and the irradiation dosages. The dose of $20 \mathrm{Krad}$ practically hinders the migration of the para sites (in both strains) from the lungs to the portal system. whereas the dose of $40 \mathrm{Krad}$ prevents the migration of most of the parasites from the skin to the lungs.

\section{AGRADECIMENTOS}

Este trabalho recebeu auxílio financeiro do CNPQ. CPQ UFMG E FINEP.

Nós agradecemos a Zenir de Souza. Alice Ne ni Faria, Alberto G. dos Santos, José de Souza Filho. Adelino Ferreira e Mauricio V. da Costa pela assistència técnica.

\section{REFERENCIAS BIBLIOGRAFICAS}

1. BARBOSA. M. A. PELLEGRINO. J : COELHO. P M Z. \& SAMPAIO. I. B. M. - Quantitative aspects of the migsation and reolutive asvnehronism of Schistosoma mansoni in mice. Rev. Inst. Ned. trop. S. Paulo, 20: 121132,1978

2. BICKLE. Q. D.; DOBINSON, T. \& JAMES, E. R. -- The efferts of gamma irradiation on migration and survival of Schistosoma mansoni schistosomula in mice. Parasitology, z9: 223230.1979

3. BICKLE, Q. D \& JAMES, E R. -- Imnunization of mice using radiation attenuated crypreserved schistosomula of Schistosoma mansoni. Trans. roy. Soc.trop. Med. Hyg. 72: 677678.1978

4. ERICKSON.D. G ... The fate of gamma irradiated Sehistosoma mansoni cercariae in mice. Amer. J. trop. Med. IIyg., 14:574578, ] 965

5. FORD, M. G.: BICKLE.Q.D.\& TAYLOR, M. G.... Immu nization of rats against Schistosoma mansoni using irra diated cercariae. lung schistosomula and liver stage worms. Parasitology, 89: 327 344. 1984

6. FREITAS. J R. - Ritmo de crescinento da Biomphalaria glabrata (Say. 1818). Padronizacto da teonica de criaça. Belo Horizonte, 1973. Tose de Dolitoramente ICB UFMG

7. GHANDOUR, A. M. \& WEBBE. G. - The effect of gamma radiation on cercariae of Schistosoma mansoni. J. Helminth., 49: $161 \quad 165.1975$

8. HSU, H. F ; LAVIS, J. R.; HSU, S. Y \& OSBORNE, J W. Histopathology in albino mice and rhesus monkeys infected with irradiated cercariae of Sehistosoma japonicum. J. Parasit., 49: 53, 1963

9. LICHTENBERG.F.V \& SADUN E. H. - Parasite migra tion and host reaction in mice 6 xposed to irradiated cerca riac of Schistosoma mansoni. Exp. Parasit., 13: 256265 1963.

10. MANGOLD, B, L. \& DEAN, D, A. -- The migration and survival of gamma irradiated Schistosoma mansoni lar vae and the duration of host parasite contact in relation to induction of resistance in mice. Parasitology, 88: 249266.1984 .

11. MASTIN, A. J.: BICKLE, Q. D. \& WILSON. R. A. - Schistosoma mansoni migration and attrition of irradiated and challenge schistosomula in the mouse. Parasitology, 87: 87102.1983

12. MILLER, K, L. \& SMITHERS. S. R. - Schistosoma mansoni: the attrition of a challenge infection in mice immu nized with highly irradiated liver cerearie. Exp. Parasit. 50: 212221,1979

13. PELLEGRINO.J. \& KATZ, N . - Infection of baby mice with Schistosoma mansoni: some biological aspects in connection with experimental chemotherapy. Trans, rov. Soc. trop. Med. Hyg., 63: 568575,1979

14. PELLEGRINO.J.\&SIQUEIRA. A. F. - Tenica de perfu sảo para colheita de Schistosoma mansoni en cobalas cxperimentalmente infestadas. Rev. bras. Malar., 8 : 589597,1959 
CARDoso, G. de S. \& COELho, P. M. Z. - Schistosoma mansoni: aspectos quantitativos da evoluçāo de cercárias irradiadas a nível da pele. pulmōes e sistema porta. em camundongos. Rev. Inst. Med. trop. S. Paulo, 31(5): 313.321 , 1989 .

15. PERLOWAGORA-SZUMLEWICZ, A. - Studies on acqui red resistance to Schistosoma mansoni in mice exposed to $\mathrm{X}$ irradiated cercariae. Bull. WId. Hith. Org., 30: $401412,1964$.

16. SHER. A.: MACKENZIE, P. E. \& SMITHERS, S. R. Decreased recovery of invading parasites from the lungs as a parameter of acquired schistosomiasis in the laboratory mouse. J. infect. Dis., 130: 626.633 .1974 .
17. SNEDECOR, G. W. \& COCHRAN, W. G. - Two way classi fication. In: SNEDECOR, G. W. \& COCHRAN, W. G. Statistical methods. $6^{\text {th }}$ ed. Iowa, State University Press. 1971. v. 2. p. 327.329

18. VILlella. J. B:; GOMBERG. H. G. \& GOULD. S. E. - Immunization to Schistosoma mansoni in mice inocu lated with radiated cercariae. Science, 134: 10731075 . 1961.

Recebido para publicação em 13/4:1989. 